\title{
Characterization of Palm Nut Shell Carbon and Treated Flyash Residue for Adsorption of Coloring Matter from Aqueous Systems
}

\author{
C. Palanivel ${ }^{1, *}$, L. D. Prabhakar ${ }^{2}$, M. Emayavaramban ${ }^{1}$ \\ ${ }^{1} \mathrm{PG}$ and Research Dept. of Chemistry, Government Arts College, C. Mutlur, \\ Chidambaram - 608102, Tamilnadu, India \\ ${ }^{2}$ Department of Chemistry, Annamalai University, Annamalai Nagar - 608 002, Tamil Nadu, India \\ *E-mail address: cpalaniivel@gmail.com
}

\begin{abstract}
The Palm Nut Shell Carbon (PNSC) and Treated Flyash Residue (TFR) has prepared by sulphuric acid process and characterized. The characterization studies includes determination of moisture, bulk density, $\mathrm{pH}$, carbon soluble in water and acid, decolourising power, iron content, phenol number and surface area parameters. The characteristics of these carbons were compared with that of high cost activated charcoal carbon (ACC). The PNSC and TFR were used for adsorption of colouring matter from the textile dyeing industrial effluents.
\end{abstract}

Keywords: Adsorption; Colouring matter; Aqueous System; ACC; PNSC

\section{INTRODUCTION}

Activated carbon adsorption for waste water treatment is well established method (Perrich) ${ }^{1}$. There are reports which indicates its uses for removal of dyes from aqueous phase (Prabhu et $\mathrm{al}^{2}$, Mckay et $\mathrm{al}^{3}$, John et $\mathrm{al}^{4}$, Ruth, yu-li ${ }^{5}$, Coelho ${ }^{6}$ ).

The traditional use of activated carbon in both water and waste water treatment is very well known. These materials are very versatile adsorbents due to their high surface area, a well developed pore structure and surface properties. Activated carbons are known to have a heterogeneous physical and chemical structure.

The significance of the carbon surface chemistry in the adsorption process was first raised by Hassler ${ }^{7}$.

In aqueous phase, the adsorption capacity of these adsorbents depends on nature (i.e. pore structure, ash content and moisture) of the adsorbate (i.e. $\mathrm{pK}_{\mathrm{a}}$, polarity, molecular weight, functional group and size) and the medium conditions (i.e. $\mathrm{pH}$, ionic strength and adsorbate concentration) ${ }^{8-10}$.

The removal of colour ${ }^{11-13}$ widly studied by various low cast materials originated from natural sources such as silica, fly ash, tea dust, rice husk, bamboo pulb etc.. The PNSC and TFR also be used for the effective adsorption of heavy metal ions.

In this direction hence in we report the investigations on the adsorption of the direct dyes i.e. Grey NS, Black E and Orange TGU by PNSC and TFR. 


\section{EXPERIMENTAL METHODS}

\section{1. Preparation of Carbons}

The palmnut shell carbon is prepared by treating four parts of dry palm nut shells with two parts of concentrated sulphuric acid (wt/wt) and keeping it in an air oven at $140-170{ }^{\circ} \mathrm{C}$ for 24 hours.

The carbonized material was filtered and washed with water to remove the excess acid and dried at $110{ }^{\circ} \mathrm{C}$ and dry palm nut shell carbon was designated as PNSC. The flyash material was treated with cold and hot running water and then with concentrated sulphuric acid at $200^{\circ} \mathrm{C}$ about 5 hours.

After heating, the flyash material was washed with various organic solvents (ether, ethanol, chloroform, benzene and acetone) and then dried in vacuum. The dry treated flyash residue was designated as TFR. The Activated Charcoal Carbon (ACC) was obtained from chemical laboratory of qualigens make and used as such. The former two carbons (PNSC and TFR) were compared with that a activated charcoal carbon (ACC). The three carbon materials (ACC, PNSC and TFR) were grounded well and sieved to an average diameter of 20-50 mesh

\section{RESULTS AND DISCUSSION}

\section{1. Characterization of carbon samples}

The carbon samples were characterized after following ISI code ${ }^{14}$ procedures and the results are summarized and tabulated in Table 1.

\section{2. SEM of carbon samples}

The shape and size of the particles of the carbon samples were examined through SEM photographs (Fig. 1-3).

The surfaces of the carbon samples were irregular and not spherical as expected. In the crystallinity is found to be more in activated charcoal carbon (ACC) than that of palm nut shell carbon (PNSC).

In the case of treated flyash residue (TFR) the conglomeration of carbon particles results into bulky mass.

This conglomeration reduces the surface area and hence except low adsorption. Another future identifiable is low degree of spherical shape. This is not present in other two samples. ACC is more crystalline but not spherical in shape.

It is found that the characteristics of PNSC and TFR are somewhat close to that of ACC. 
Table 1. Characterization of carbon samples

\begin{tabular}{|c|c|c|c|c|}
\hline S. No. & Parameters & ACC & PNSC & TFR \\
\hline 1. & Moisture content (\%) & 20.8 & 15.2 & 13.6 \\
\hline 2. & Ash content (\%) & 0.21 & 0.72 & 0.42 \\
\hline 3. & Bulk density (g/cc) & 0.47 & 0.67 & 0.74 \\
\hline 4. & pH & 7.9 & 6.8 & 7.8 \\
\hline 5. & Carbon soluble in water (\%) & 0.95 & 0.97 & 0.94 \\
\hline 6. & Carbon soluble in acid (\%) & 1.95 & 1.05 & 1.81 \\
\hline 7. & $\begin{array}{c}\text { Decolourizing power (mg/g) methylene } \\
\text { blue }\end{array}$ & 112.5 & 73.0 & 72.0 \\
\hline 8. & $\begin{array}{c}\text { Iron content }\left(\times 10^{-6} \text { gm/gram of }\right. \\
\text { carbon) }\end{array}$ & 811.0 & 1054.3 & 405.5 \\
\hline 9. & Surface area (m $/ \mathrm{g})$ & 474.3 & 459.1 & 467.9 \\
\hline 10. & \begin{tabular}{c} 
Ion exchange capacity $(\mathrm{mg} / \mathrm{g})$ \\
\hline 1.
\end{tabular} & 0.4468 & 0.3277 & 0.3872 \\
\hline
\end{tabular}

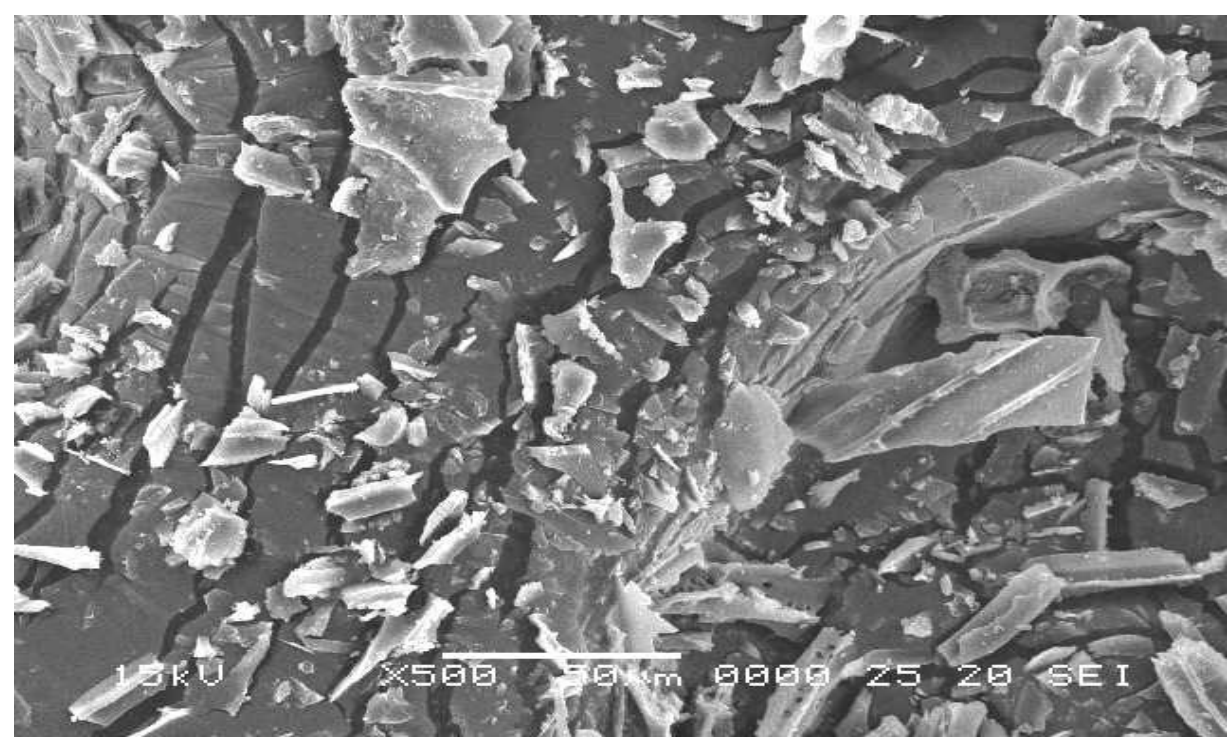

Fig. 1. Activated Charcoal Carbon (ACC) 


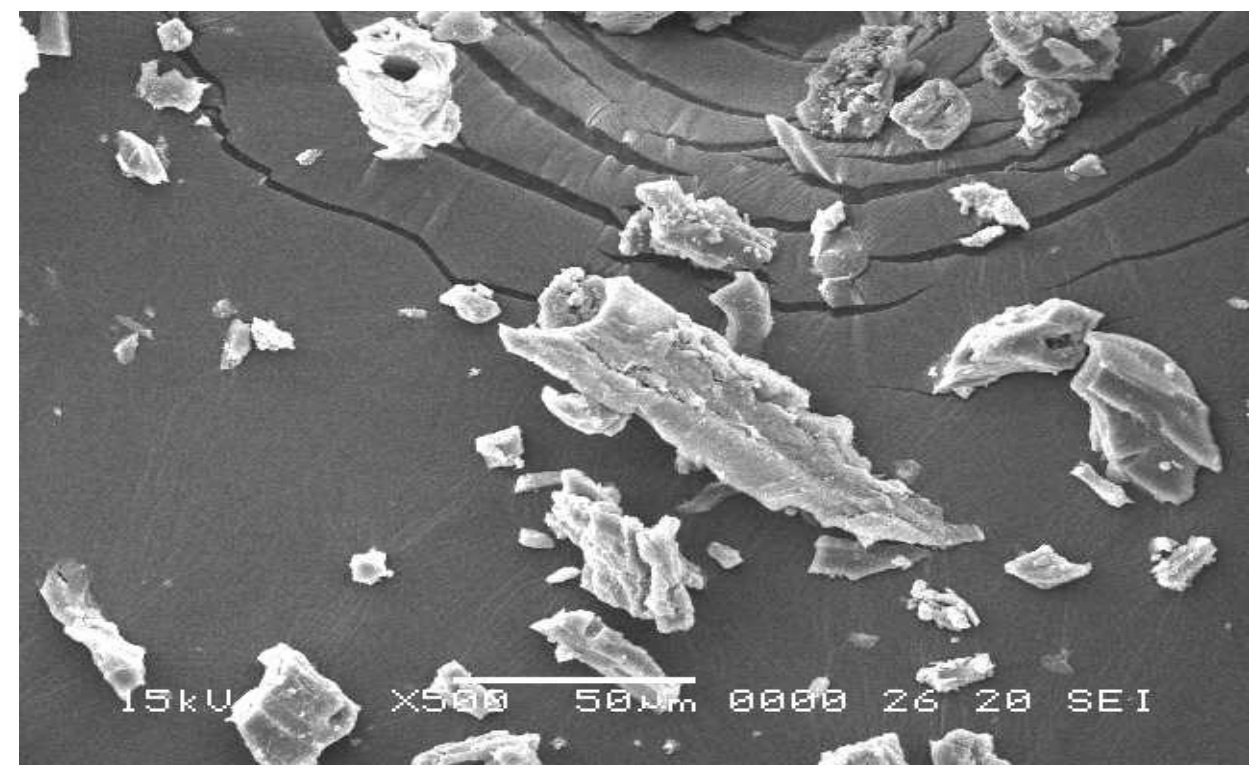

Fig. 2. Palm Nut Shell Carbon (PNSC)

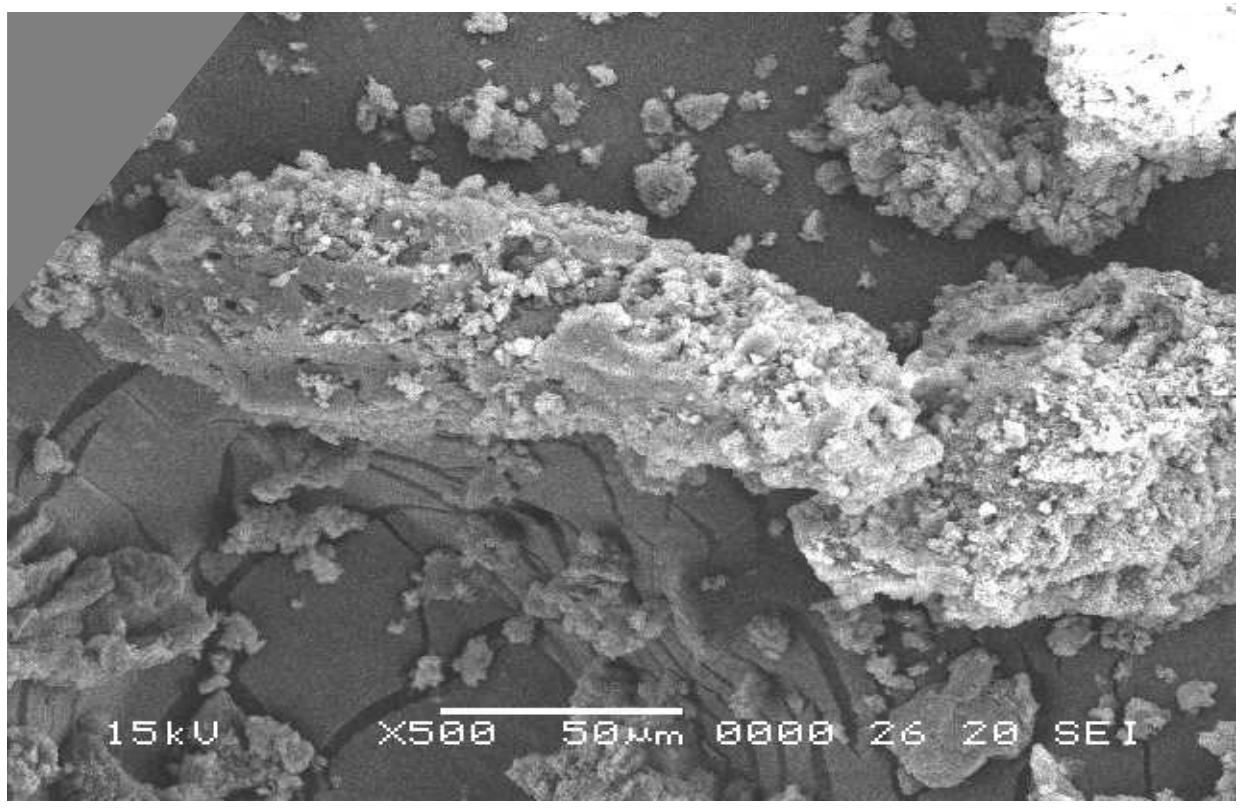

Fig. 3. Treated Flyash Residue (TFR)

\section{3. Application of the carbons}

The prepared carbons were found to be close in properties to that of activated charcoal carbon. These carbons have been used to adsorb the colouring matter from the aqueous textile industrial waste. Among various dyes tested nearly 3 direct dyes are observed to be adsorbed effectively. The various optimum conditions for the three direct dyes have been studied as presented as show below. 
Table 2. Carbon - I (ACC)

\begin{tabular}{|c|c|c|c|c|}
\hline S. No. & Parameters & $\begin{array}{c}\text { Grey NS } \\
\left(\lambda_{\max }: 580 \mathrm{~nm}\right)\end{array}$ & $\begin{array}{c}\text { Black E } \\
\left(\lambda_{\max }: 585 \mathrm{~nm}\right)\end{array}$ & $\begin{array}{l}\text { Orange TGU } \\
\left(\lambda_{\max }: 405 \mathrm{~nm}\right)\end{array}$ \\
\hline 1. & $\mathrm{pH}$ & 6 & 9 & 7.5 \\
\hline 2. & Carbon dose (g) & 0.9 & 0.9 & 0.8 \\
\hline 3. & Equilibration period (min.) & 330 & 360 & 240 \\
\hline 4. & Reusable cycles & 4 & 5 & 5 \\
\hline \multirow[t]{7}{*}{5.} & Isotherm characteristics & & & \\
\hline & i. Langmuir constant & & & \\
\hline & a. Sorption intensity (a) & 0.358 & 0.234 & 0.626 \\
\hline & b. Adsorption capacity (b) & 0.571 & 0.532 & 0.427 \\
\hline & ii. Freundlich constant & & & \\
\hline & a. $\mathrm{K}$ & 0.219 & 0.148 & 0.225 \\
\hline & b. $1 / \mathrm{n}$ & 0.315 & 0.406 & 0.222 \\
\hline 6. & $\begin{array}{l}\text { Relationship of bed depth } \\
\text { and service time analysis }\end{array}$ & $\mathrm{S}=0.58+85.6 \mathrm{~b}$ & $S=0.43+80.6 b$ & $\mathrm{~S}=0.35+92.8 \mathrm{~b}$ \\
\hline \multirow[t]{5}{*}{7.} & Kinetic parameters & & & \\
\hline & $\begin{array}{l}\text { i. Overall rate constant } \\
(\mathrm{K})^{(\mathrm{b})}\end{array}$ & -0.6628 & -0.9453 & -0.6484 \\
\hline & $\begin{array}{l}\text { ii. Forward rate constant } \\
\left(\mathrm{k}_{1}\right)^{(\mathrm{b})}\end{array}$ & $-2.651 \times 10^{-4}$ & $-1.890 \times 10^{-4}$ & $-6.483 \times 10^{-5}$ \\
\hline & $\begin{array}{l}\text { iii. Backward rate constant } \\
\qquad\left(\mathrm{k}_{-1}\right)^{(\mathrm{b})}\end{array}$ & -0.6625 & -0.9451 & -0.6483 \\
\hline & $\begin{array}{l}\text { iv. Equilibrium constant } \\
\left(\mathrm{k}_{\mathrm{C}}\right)^{(\mathrm{b})}\end{array}$ & $4.002 \times 10^{-4}$ & $2.000 \times 10^{-4}$ & $-1.000 \times 10^{-4}$ \\
\hline
\end{tabular}

Note:

(a) Service time $=30 \mathrm{~min}$

(b) Initial dye concentration $=10 \mathrm{mg} / \mathrm{L}$ 
Table 3. Carbon - II (PNSC)

\begin{tabular}{|c|c|c|c|c|}
\hline S. No. & Parameters & $\begin{array}{c}\text { Grey NS } \\
\left(\lambda_{\max }: 580 \mathrm{~nm}\right)\end{array}$ & $\begin{array}{c}\text { Black E } \\
\left(\lambda_{\max }: 585 \mathrm{~nm}\right)\end{array}$ & $\begin{array}{c}\text { Orange TGU } \\
\left(\lambda_{\max }: 405 \mathrm{~nm}\right)\end{array}$ \\
\hline 1. & $\mathrm{pH}$ & 7 & 7 & 7.5 \\
\hline 2. & Carbon dose $(\mathrm{g})$ & 0.8 & 1.1 & 0.5 \\
\hline 3. & Equilibration period (min.) & 240 & 360 & 240 \\
\hline 4. & Reusable cycles & 4 & 5 & 5 \\
\hline \multirow[t]{7}{*}{5.} & Isotherm characteristics & & & \\
\hline & i. Langmuir constant & & & \\
\hline & a. Sorption intensity (a) & 0.304 & 0.748 & 0.222 \\
\hline & b. Adsorption capacity (b) & 0.752 & 0.637 & 0.503 \\
\hline & ii. Freundlich constant & & & \\
\hline & a. $\mathrm{K}$ & 0.276 & 0.378 & 0.109 \\
\hline & b. $1 / \mathrm{n}$ & 0.315 & 0.180 & 0.538 \\
\hline 6. & $\begin{array}{l}\text { Relationship of bed depth and } \\
\text { service time analysis }\end{array}$ & $S=0.45+87.5 b$ & $S=0.16+95.9 b$ & $\mathrm{~S}=0.12+97.3 \mathrm{~b}$ \\
\hline \multirow[t]{5}{*}{7.} & Kinetic parameters & & & \\
\hline & i. Overall rate constant $(\mathrm{K})^{(\mathrm{b})}$ & -1.1386 & -0.5027 & -0.8493 \\
\hline & ii. Forward rate constant $\left(\mathrm{k}_{1}\right)^{(\mathrm{b})}$ & $-9.113 \times 10^{-4}$ & $-7.539 \times 10^{-4}$ & $-4.244 \times 10^{-5}$ \\
\hline & $\begin{array}{l}\text { iii. Backward rate constant } \\
\qquad\left(\mathrm{k}_{1}\right)^{(\mathrm{b})}\end{array}$ & -1.1376 & -0.5019 & -0.8489 \\
\hline & iv. Equilibrium constant $\left(\mathrm{k}_{\mathrm{C}}\right)^{(\mathrm{b})}$ & $0.801 \times 10^{-3}$ & $1.502 \times 10^{-3}$ & $0.500 \times 10^{-3}$ \\
\hline
\end{tabular}

Note:

(a) Service time $=30 \mathrm{~min}$

(b) Initial dye concentration $=10 \mathrm{mg} / \mathrm{L}$ 
Table 4. Carbon - III (TFR)

\begin{tabular}{|c|c|c|c|c|}
\hline S. No. & Parameters & $\begin{array}{c}\text { Grey NS } \\
\left(\lambda_{\max }: 580 \mathrm{~nm}\right)\end{array}$ & $\begin{array}{c}\text { Black E } \\
\left(\lambda_{\max }: 585 \mathrm{~nm}\right)\end{array}$ & $\begin{array}{c}\text { Orange TGU } \\
\left(\lambda_{\max }: 405 \mathrm{~nm}\right)\end{array}$ \\
\hline 1. & $\mathrm{pH}$ & 7 & 7 & 8 \\
\hline 2. & Carbon dose (g) & 0.5 & 1.0 & 0.9 \\
\hline 3. & Equilibration period (min.) & 210 & 330 & 240 \\
\hline 4. & Reusable cycles & 4 & 5 & 5 \\
\hline \multirow[t]{7}{*}{5.} & Isotherm characteristics & & & \\
\hline & i. Langmuir constant & & & \\
\hline & a. Sorption intensity (a) & 0.182 & 0.266 & 0.133 \\
\hline & b. Adsorption capacity (b) & 0.654 & 0.503 & 0.671 \\
\hline & ii. Freundlich constant & & & \\
\hline & a. $\mathrm{K}$ & 0.119 & 0.129 & 0.110 \\
\hline & b. $1 / \mathrm{n}$ & 0.588 & 0.473 & 0.555 \\
\hline 6. & $\begin{array}{l}\text { Relationship of bed depth and } \\
\text { service time analysis }\end{array}$ & $S=0.19+95.8 b$ & $\mathrm{~S}=0.21+95.2 \mathrm{~b}$ & $s=0.30+93.7 b$ \\
\hline \multirow[t]{5}{*}{7.} & Kinetic parameters & & & \\
\hline & i. Overall rate constant $(\mathrm{K})^{(\mathrm{b})}$ & -0.7432 & -0.7087 & -0.7317 \\
\hline & ii. Forward rate constant $\left(\mathrm{k}_{1}\right)^{(\mathrm{b})}$ & $-7.877 \times 10^{-3}$ & $-8.787 \times 10^{-3}$ & $-2.561 \times 10^{-3}$ \\
\hline & $\begin{array}{l}\text { iii. Backward rate constant } \\
\left(\mathrm{k}_{-1}\right)^{(\mathrm{b})}\end{array}$ & -0.7353 & -0.6999 & -0.7291 \\
\hline & iv. Equilibrium constant $\left(\mathrm{k}_{\mathrm{C}}\right)^{(\mathrm{b})}$ & $10.713 \times 10^{-3}$ & $12.555 \times 10^{-3}$ & $3.512 \times 10^{-3}$ \\
\hline
\end{tabular}

Note:

(a) Service time $=30 \mathrm{~min}$

(b) Initial dye concentration $=10 \mathrm{mg} / \mathrm{L}$ 


\section{CONCLUSION}

The carbons (PNSC \& TFR) are prepared from locally available cheap materials like, palm nut shells and fly ash. The properties of ( PNSC \& TFR) are closed with ACC. The three direct dyes, grey NS, black E, and orange TGU are obtained by commercially and using these dyes coloured solutions are prepared. The carbon have been used to adsorb the colouring matter from three dyes solution and to be adsorbed effectively. Large scale removal of the dye is happening with equilibrium build up after 1 hour The adsorption of the dye depends upon the initial concentration of the dye and upon $\mathrm{pH}$ condition and the carbon after use can be disposed without any effects are burnt easily. The carbon can be reused at least five times without much reduction in the adsorption capacity. The Langmuir and freundlich constant are calculated for all the dyes and also bed depth service time analysis has been done and depth to time dependency has been evaluated.

\section{References}

[1] Perrich J. R., Activated carbon adsorption for waste water, Treatment. CRC Press, INC., Boca raton, Florida 1981.

[2] Prabhu H., Kaspar A., Textile dyer printer 27(22) (1994) 19-21.

[3] McKay G., Al-Duri B., Chemical Engineering Journal 83 (2001) 15-23.

[4] John P. B., Hutchins R. A., Chemist. Colourist. 8(4) (1975) 34.

[5] Ruth Yu-Liyeh., J. Chem. Tech. Biotech. 63 (1995) 55-59.

[6] Coelho Esteves A. M., Env. Sci. Res. 42 (1991) 797-805.

[7] Hassler J. W., Chemical Publishing Co., Inc. New York, 127 (1951).

[8] Nouri S., Haghseresht F., Lu G., Inter. J. Eng. Sci. 12 (2001) 67.

[9] Nouri S., Journal of Amir Kabir 4 (1970) 64.

[10] Nouri S., Adsorption Science and Technology 19 (2001) in press.

[11] Manivannan V., Colour removal and dye houses waste water, Ph.D. Thesis Madras University, Madras 1985.

[12] Khare S. K., Pandey K. K., Srivastava R. M., Singh V. N., J. Chem. Technol. Biotechnol. 38(2) (1987) 99.

[13] Ahmed M. N., Ram R. N., J. Environ. Pollut. 37(2) (1992) 131.

[14] Methods of sampling and tests for activated carbon used for decolourising vegetables oils and sugar solutions, ISI - 877 (1977). 